DOI: 10.1515/pcssr-2015-0023

\title{
Research on Relative Age in Hungarian Swimming
}

Authors' contribution:

A) conception and design of the study

B) acquisition of data

C) analysis and interpretation of data

D) manuscript preparation

E) obtaining funding
Nikoletta Nagy $^{\text {A-E }}$, Csaba Ökrös ${ }^{\text {A-E }}$, Csaba Sós ${ }^{\text {A-E }}$

University of Physical Education, Budapest, Hungary

KEYWORDS

\begin{abstract}
In 2017, the $19^{\text {th }}$ World Swimming Championship will be organized in Hungary. Up to now, many people have already been working with swimmers to achieve good results. However, in the next period they must work even harder to ensure that the national swimmers of a country as small as Hungary can achieve the outstanding results of their predecessors. Since high-level competitions in swimming have become more intense, innovations including scientific studies are needed during preparation for the event. The purpose of this paper is to present the major results of an independent study carried out by the authors about the relative age of the best Hungarian swimmers with the aim of contributing to their preparation. The research population consisted of selected age groups of swimmers registered by the Hungarian Swimming Association $(\mathrm{N}=400)$. The method for data collection was an analysis of documents. To evaluate the data, the Chi-square and Kruskal-Wallis tests were used. The results are presented according to the period of the competitor's date of birth, gender, and age group. The results confirm only partly the hypothesis that people born in the first quarters of the year play a dominant role in Hungarian national swimming teams. In the conclusion, the authors recommend further research on relative age in swimming and in other sports.

relative age, swimming, age groups, competitive sports
\end{abstract}

\section{Introduction}

\section{The justification of choosing the topic}

Hungarians have been proud of the great results of their swimmers for generations. From the recent great achievements, Katinka Hosszu's serial successes and Daniel Gyurta's and Laszlo Cseh's respectable performances at the Olympic games and world championships must be mentioned. The results of the Hungarian swimmers reflect their long and heavy training and the outstanding professional work of their coaches.

The sport of swimming in Hungary faces a new challenge: in 2017 , the $19^{\text {th }}$ World Swimming Championship will be organized in Hungary, and it is expected that the national swimmers should 
be unbeatable again and that many of them will come out on top. Up to now, many people have already been working with swimmers to achieve good results. However, in the next period they must work even harder to ensure that the national swimmers of a country as small as Hungary can achieve the outstanding results of their predecessors. Since high-level competitions in swimming have gotten tougher, innovations are needed during the preparation. The continuously broken records and the technological innovations justify the need for scientific research. Therefore, an independent study was carried out by the authors of this paper with the aim of contributing to the preparations of the Hungarian swimmers. This research dealt with the relative age of the Hungarian swimmers.

\section{Review of related literature}

The related literature deals in part with athletes' birth dates in a calendar year; in part, they examine the advantages of the Relative Age Effect (RAE) for athletes who were born earlier in a given year. This brief review analyzes some works which focused their attention not on young athletes, but on athletes of all ages - not only in swimming, but in other sports as well.

The idea of studying the role of relative age has become more and more important since 1985 when it was revealed that $40 \%$ of the players in the Canadian Hockey Championship were born in the first quarter of the calendar year (Barnsley et al., 1985). From this time on, relative age came into the limelight and has been studied in different sports and in various age groups from several perspectives. It became an important research field in ball games; hockey players (Sherar et al., 2007; Hancock et al., 2013), rugby players (Roberts, \& Fairclough, 2012), and soccer players (Helsen et al., 2005; Vincent, \& Glamser, 2006; Nakata, \& Sakamo, 2011; Salinero et al., 2013) were examined from this perspective. The importance of the theme is also reflected by the fact that several researchers whose countries of origin are successful in the world of soccer, like France (Delorme et al., 2010), Germany (Augste, \& Lales, 2011), Brazil (Rogel et al., 2007), and Spain (Gutiérrez-Díaz et al., 2010), dealt with it as a highlighted topic.

The effect of relative age on athletic performance was also investigated in sports where rivals are separated from each other with a net. It was found to be a considerable factor in badminton (Nakata, \& Sakamoto, 2011), volleyball (Nakata, \& Sakamoto, 2011; Okazaki et al., 2011), and tennis (O’Donoghue, 2009; Loffing et al., 2010). A few months of advantage in the same age category did not prove to be significant in taekwondo (Alberquerque et al., 2012), golf, or horseback riding (Nakata, \& Sakamoto, 2011).

The significance of relative age was also studied in sports where certain physical features (bodyweight, body height, strength) are dominant. García-Álvarez and Salvadores (2005) examined children under the age of 15 . They found $10 \mathrm{~cm}$ difference in body height and $10 \mathrm{~kg}$ difference in body weight among children who were born in the same calendar year. Malina's study (1994) supports the assumption that an age difference of 11 months in the same age category can have a significant effect on performance because of the huge differences in the body height and body weight of athletes.

Ford et al. (2008) found just the contrary. They examined 180 successful athletes, and they could not prove the impact of relative age. In fact, they discovered just the opposite. Baxter-Jones et al. (1995) stated that the effect of relative age depends to a great extent on the character of a given sport. For example, in gymnastics, where an increasing body height and body weight influence performance negatively, the RAE might create a disadvantage for children who were born earlier.

The relatively few studies that were carried out on relative age in swimming, generally speaking, approach the issue from the point of view of equal opportunity. Their findings support the statement that athletes who are younger in their age group have an advantage to perform better, not only in their youth, but in later periods of life as well. A gender study of a population of master athletes (Medic et al., 2011) stated that although relative age is a more important determining factor for senior female swimmers, it should be taken into consideration at competitions with both genders in order to guarantee equal conditions. In a longitudinal study dealing with senior swimmers, it was discovered that their participation in competitions was twice as frequent in the first five years following their retirement than in the later 
periods of their disengagement from elite sports, and the relatively older swimmers attained better results (Medic et al., 2011).

Concerning the younger generations, Portuguese swimmers between the ages of 12 and 18 were examined from the point of view of relative age. Research results related to their achievements showed the effect of relative age in 12-year-old girls and in boys between the ages of 12 and 15, although the post hoc test didn't present a significant difference. On the other hand, it found that the majority of adult swimmers belonging to the top 50 were born in the first two quarters of the year, especially those of the male gender (Costa et al., 2013).

In the opinion of Dixon et al. (2011), children who were born relatively earlier in a given age group have an advantage over their younger group-mates in both education and sports. Nevertheless, the impact of relative age on sporting performance wasn't found to be significant in some sports (Medic et al., 2007).

\section{Clarifying the major terms}

The term of relative age in geology and in archeology means the comparison of the age of objects or events to other objects or events without knowing/ defining their age in terms of years. With people, relative age refers to the differences between the amount of years a person has been alive since birth (chronological age) and their body's real age - that is, the rate at which they are aging (biological age). People whose bodies function well can be younger biologically than chronologically.

In sports, it is recognized that athletes' chronological and biological ages are not always the same, and these differences have a special significance in young athletes. Not only the year, but also the month of the birth of young athletes may be significant. Accordingly, relative age can be defined as the differences in age that originate from the differences in the birth dates of people within the same age group. A new concept called the Relative Age Effect (RAE) was introduced which is defined as "a phenomenon that suggests that athletes at the elite level are more likely to be born in the first 3 months after the eligibility cut-off date for a particular age group in sports" (Douglas, 2015). It is suggested that those athletes who were born earlier in the calendar year may have an advantage, especially in sports that are more physically demanding and when the competition is tough (Delorme et al., 2010). Therefore, the importance of age measured using a calendar may differ depending on the circumstances.

\section{Talent care and evaluation system in Hungarian swimming}

Talent care in Hungary begins with the selection of talented children at the time they are learning to swim and continues with the management of the most gifted children by the Hungarian Swimming Association.

This means that young swimmers are grouped into six groups according to their birth dates: frog (7-8 years), dolphin (9-10 years), children (girls: 11-12 years; boys: 11-12 and 13-14 years), adolescent (girls: 1314 years; boys: 15-16 years), junior (girls: 15-16 years; boys: 17-18 years), and adult (girls: 17 and over; boys: 19 and over).The age categories are determined by the Association. The swimmers compete according to their age groups. In competitions, they are classified into classes which differ slightly from the international practice because all age groups include two age-grades in Hungary. Their achievement in the national championships is evaluated in accordance with the categories they are classified into. The qualifying times are determined according to their ages, too. The Hungarian system is similar to those systems in which children can compare their developments with the progress of other swimmers in their age group (Medic et al., 2011).

Since the successfulness of Hungarian swimmers is influenced by the percentage of talented children who can reach the adult age group, the development of 11-12 year old children is managed with particular care. A program called "Champions of the Future" was introduced for them a few years ago. This program pays special attention to the progress of children in this age group. 


\section{Objectives}

Age groups are created in sport to guarantee equal opportunity while evaluating the achievements of athletes. The establishment of age categories has special importance for people of a young age. In swimming, a child's size may give him or her an advantage, but a review of the related literature does not prove unambiguously that late developers are discriminated against in talent selection.

There is especially little knowledge about the effect of relative age in cases when two age groups are evaluated together, as in Hungarian swimming, since there are sometimes 20-22 months of age difference between children who are evaluated together. Since the promotion of fairness and equality is considered to be a fundamental principle in Hungarian sports, and the successfulness of the national swimming also depends on proper talent selection, the authors intended to discover the effect of relative age on swimming in Hungary. They carried out a study with the purpose to find answers to the following questions: In which period of the year were the best Hungarian swimmers born? Is there a tendency to select swimmers based on when they were born?

Through this study, the authors aimed to lend a helping hand to the experts and to make the process of selection and the assessment system more acceptable and more just.

The aim of this paper is to present the major results of this study.

\section{Hypotheses}

We proceeded from the following hypotheses.It was assumed that:

1. The majority of the best Hungarian swimmers in all examined age groups were born in the first two quarters of the year;

2. The most examined outstanding swimmers were born in the first quarter of the year;

3. There are no differences in the relative age of the best Hungarian swimmers according to gender;

4. The most examined Hungarian swimmers were born in January, February, and March, regardless of age group.

\section{Material and methods}

The research population of our study consisted of the adult, junior, and adolescent members of the Hungarian national swimming team and competitor swimmers in the dolphin and children age groups from the "Champions of the Future" program ( $\mathrm{N}=400,217$ boys and 183 girls). Every young swimmer is registered in the official database of the Hungarian Swimming Association on the basis of a professional exam. The data from the children- and dolphin-aged swimmers were obtained from the official publication of the document entitled "Champions of the Future". They were selected by the Association ( $n=281$ ).

In the case of adolescents, juniors, and adults $(n=119)$ the source of data was the official website of the Association (http://musz.hu). They were selected on the basis of the results they achieved in special competitions. Members of the national team were also selected by the Hungarian Swimming Association on the basis of their achievements.

Regarding the age categories, 141 swimmers belonged to the dolphin age group, 159 to the children age group, 36 to the adolescent age group, and 64 to the junior and adult age groups. Their mean age is 13.11 years.

The method for data collection was document analysis. The swimmers in the junior and adult age groups regularly participate together in national training camps and must fulfill the same tasks. They represent Hungary in the same category at international competitions: the junior swimmers participate in senior competitions: the National Championship and the World Championship. Therefore, research findings concerning these two age groups were treated together. Moreover, since research on homogeneity 
between genders did not suggest a significant difference $(\mathrm{p}=0.089)$, data from both genders were treated together during the analysis of the findings.

Following the method used by previous studies (Carling et al., 2009; Costa et al., 2013), the exact birth date of the swimmers was used for analysis.

The data were processed with the statistical program SPSS 21.0. The 0.005 limit of error was regarded as the base for determining the level of significance $(\mathrm{p}<0.005)$. The mean and standard deviation of the chosen variables were determined. The Chi-square test was adapted to examine the difference within the same sub-sample. For comparing the age group sub-samples with different sample sizes, the KruskalWallis test wasapplied.

\section{Results}

According to the results, the examined swimmers $(\mathrm{N}=400)$ were born in the following quarters of the year, on the basis of their of birth data: 39.5\% $(n=158)$ in the first quarter, $28 \%(n=112)$ in the second quarter, $20 \%(n=80)$ in the third quarter, and $12.5 \%(n=50)$ in the fourth quarter (Figure 1).

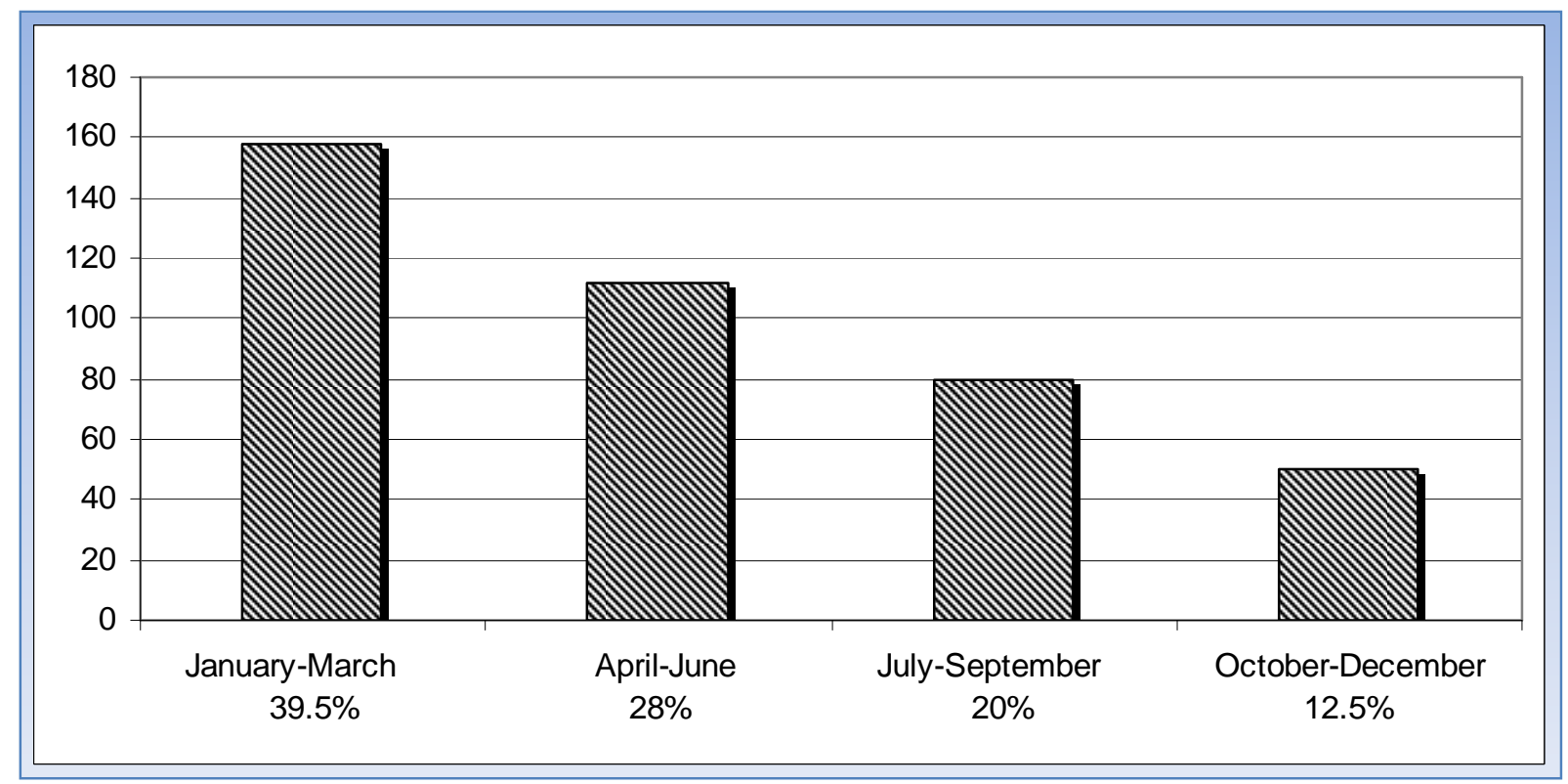

Figure 1. Distribution of the best Hungarian swimmers' birth dates according to quarter $(\mathrm{N}=400)$ Source: own study.

Regarding the months, the most examined swimmers were born in January (66 persons) and in March (51 persons). The number of swimmers who were born later than March decreased every month. In November and December, 16 swimmers were born in both months.

The numbers of birth dates according to months were analyzed with the help of the Chi-square test. Significant differences were found between the swimmers' birth dates according to month ( $\mathrm{p}=0.000$; Figure 2 ).

Gender differences regarding the season of the swimmers' births were also examined. The results of the Kruskal-Wallis test did not show any significant differences between male and female swimmers in this respect $(\mathrm{p}=0.896)$.

Gender differences regarding the season of the swimmers' births were examined in each age group as well. The results of the Kruskal-Wallis test did not reveal significant differences between boys and girls within any age group, either (dolphin: $\mathrm{p}=0.785$; children: $\mathrm{p}=0.961$; adolescent: $\mathrm{p}=0.672$; junior and adult: $\mathrm{p}=0.703)$. 


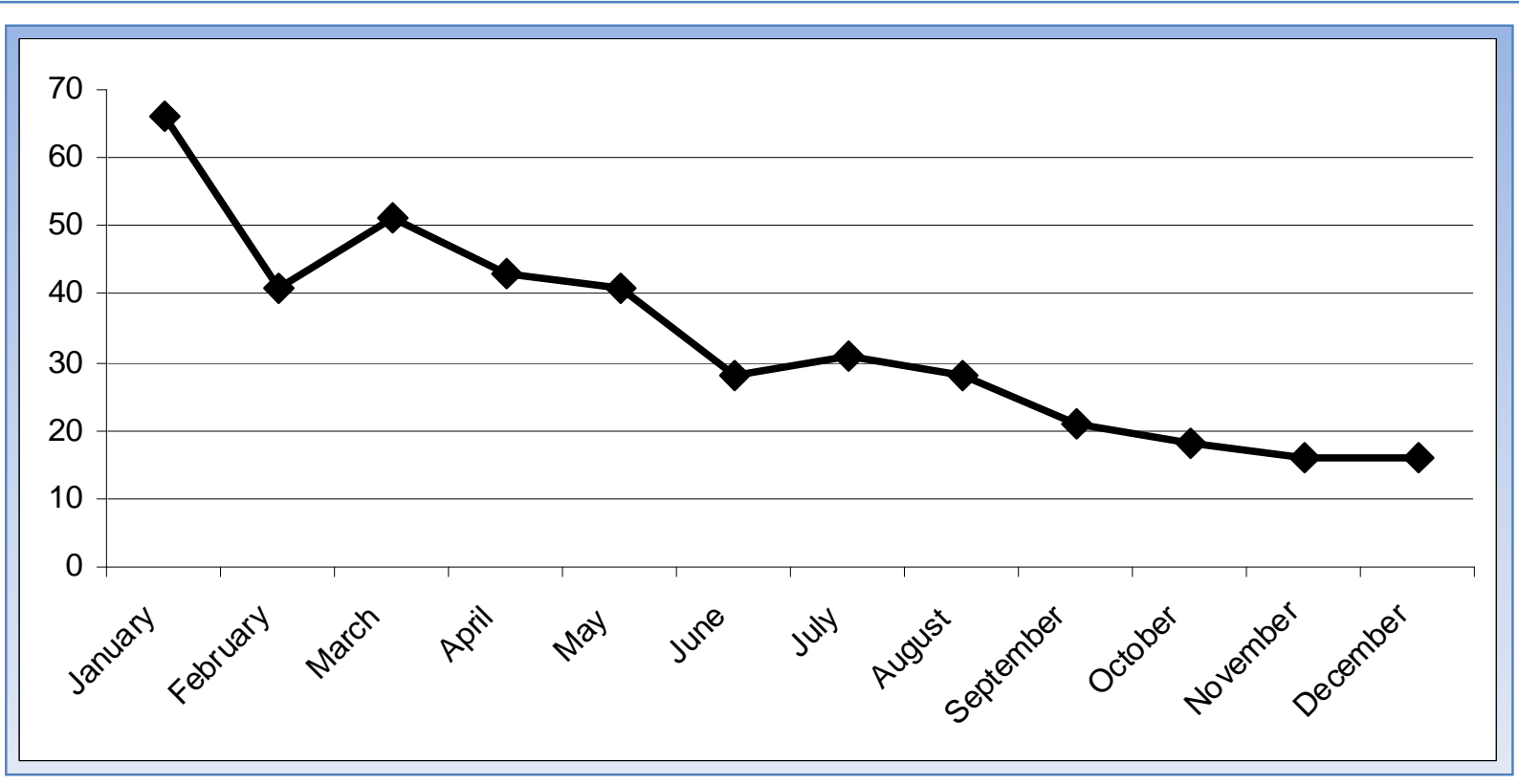

Figure 2. Distribution of the best Hungarian swimmers according to the month of their birth $(\mathrm{N}=400)$ Source: own study.

Regarding the age groups, the findings of our research revealed that the majority of the best swimmers in the dolphin and adolescent groups were born in the first quarter of the year. In the junior and adult age groups, most birth dates occurred in the second quarter of the year. The number of birth dates gradually decreases from the first quarter to the fourth quarter in the dolphin and children age groups. With the adolescents, the number of birth dates decreases until the third quarter, but it increases slightly in the fourth quarter. In the junior and adult age groups, the least number of swimmers were not born in the fourth quarter either (Figure 3).

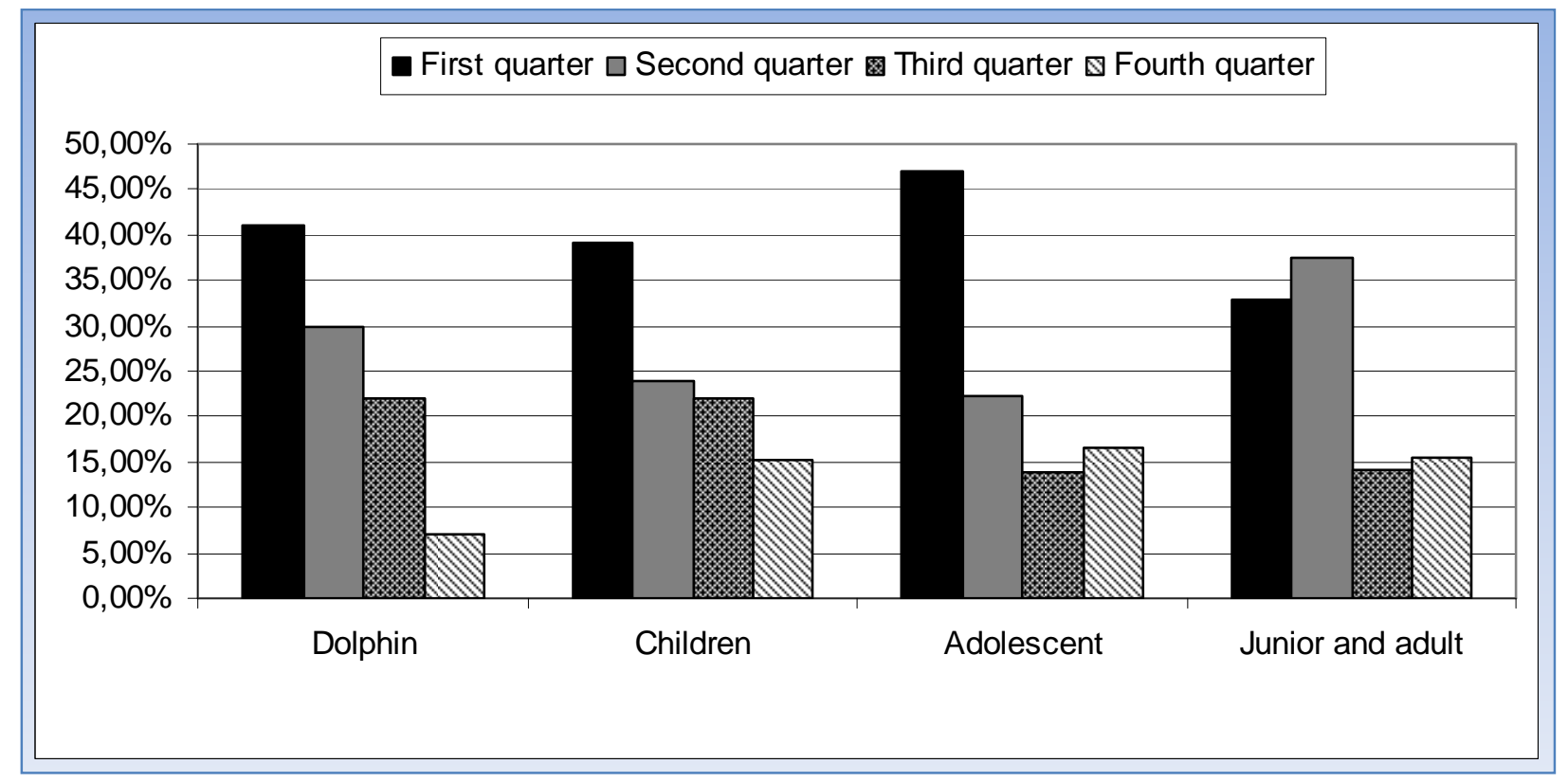

Figure 3. Distribution of the best Hungarian swimmers according to the quarter of their birth by age group $(\mathrm{N}=400)$ Source: own study.

The results of the Chi-square test indicated significant differences between the quarters within every age group (dolphin group: $\mathrm{p}=0.000$; children group: $\mathrm{p}=0.000$; adolescent group: $\mathrm{p}=0.019$; junior and adult groups: $\mathrm{p}=0.012$ ). 


\section{Conclusions}

The above results justify our first assumption, which was that the majority of the best Hungarian swimmers were born in the first and second quarters of the year. Our second hypothesis was also verified, since the swimmers born in January, February, and March form 39.5\% of the examined population. This result is similar to the research findings of Barnsley et al. (1985) concerning Canadian hockey players. In their case, $40 \%$ of the players were born in the first season of the year.

An analysis of some relevant works in the international literature show that the results of our research are similar to the results of other investigations carried out on this topic, according to which the athletes who were born in the first two quarters of the year have a higher chance of becoming the best in their age group and, later, members of national teams (Musch, \& Hay, 1999; Musch, \& Grondin, 2001; Cobley et al., 2009). Thus, the findings of our investigation support the conclusions of previous studies which suggest that relative age might have an impact on athletes' sporting careers and on the way of becoming an elite athlete.

Our third hypothesis, which supposed that there are no differences in the relative ages of the best Hungarian swimmers according to gender, was also verified: gender differences could not be found in this respect in the total research population or in the individual age groups.

The findings of our research only partly verified the fourth hypothesis, since it was revealed that there were significantly more swimmers born in the first quarter of the year than those born later only in the dolphin, children, and adolescent age groups. In the junior and adult age groups, the number swimmers born in the second quarter of the year was the highest. It seems that the importance of relative age diminishes with increasing age.

Moreover, the fact that $15.6 \%$ of elite swimmers were born in the second half of the year suggests that, although their chances are lower, the very best of them are able to become members of the national team. The most talented children who were born in November or in December could reach the top level as adults.

Before reaching the junior age, the preponderant majority of elite swimmers were born in the first season of the year. These results are similar to those of Costa et al. (2013), who studied this issue among the young generation of swimmers. They found that the effect of relative age is most important between the ages of 12 and 15 in regards to both genders.

In conclusion, it can be stated that relative age is an influencing factor in who becomes an elite Hungarian swimmer in every age group. During selection, preferences are given to swimmers who were born in the first quarter of the year. However, relative age must not be considered to be an absolutely decisive factor; there are other factors which might have a serious impact on the sporting careers of the athletes as well. In some cases, some outstanding swimmers who were born in the last quarter of the year could also be selected for the national team.

Finally, based on our experience, we think that in the future it would be worthwhile to extend research on a similar topic in swimming in order to help improve the evaluation system and to determine a more just qualification time for the national championships. In light of our research findings, it is necessary to rethink whether it is effective to evaluate children in two age-grades in the same way and to determine the same qualification time for them. Since there can be significant differences in the development of children who were born in different periods of the same year, it can be rightly supposed that the differences between the sporting performances of children who were born in different years can be even bigger. As a consequence of being evaluated similarly, some younger children can have the feeling that the evaluation system is unfair, and they can lose their motivation progress in training and in competitions. On the other hand, children who are successful early on just because of their size and maturation might be discouraged later when the other children catch up with them.

Based on our research, we are sure that it would be useful to examine the effect of relative age not only in swimming, but in other sports as well. Joining the suggestion of Gonzales-Villore and Paster- 
Vicendo (2012), we advise a more thorough analysis of this theme in a wider context in order to create age groups in sports in a way that is as fair as possible.

\section{REFERENCES}

Alburquerque, M.R., Lage, G.M., Da Costa, V.T., Ferreira, R.M., Penna, E.M., Albur- Querque, L.C.C., \& Fernandes, L. (2012). Relative age effect in Olympic taekwondo athletes. Perceptual and Motor Skills, 114(2), 461-468.

Augste, C., \& Lales, M. (2011). The relative age effect and success in German elite U-17 soccer teams. Journal of Sports Sciences, 29(9), 983-987.

Barnsley, R.H., Thompson, A.H., \& Barnsley, P.E. (1985). Hockey success and birthdate: the relative age effect. CAHPER Journal, 51(8), 23-28.

Baxter-Jones, A. (1995). Growth and development of young athletes: Should competition levels be age related? Sports Medicine, 20, 59-64.

Carling, C., Le Gall, F., Reilly, T., \& Williams, A.M. (2009). Do anthropometric and fitness characteristics vary according to birth date distribution in elite youth academy soccer players? Scandinavian Journal of Medicine and Science in Sports, 19(1), 3-9.

Cobley, S., Baker, J., Wattie, N., \& Mckenna, J. (2009). Annual age-grouping and athlete development: A metaanalytical review of relative age effects in sports. Sports Medicine, 39(3), 235-256.

Costa, Aldo M., Marques, Mário C., Louro, Hugo, Ferreira, Sandra S., Marinho, Daniel A. (2013). The relativeageeffectamongeliteyouthcompetitiveswimmers. European Journal of Sport Science, 13(5).

Delorme, N., Boiché, J., \& Raspaud, M. (2009). The Relative Age Effect in Elite Sport: The French Case. Research Quarterly for Exercise and Sport,80(2), 336-344.

Delorme, N., Boiché, J., \& Raspaud, M. (2010). Relative age effect in elite sports: methodological bias or real discrimination? European Journal of Sport Science, 10(2), 91-96.

Dixon, J., Horton, S., Weir, P. (2011). Relative Age Effects: Implications for Leadership Development. The International Journal of Sport and Society, 2(2).

Douglas, M. (2015). Relative Age Effect. Retrieved August 5, 2015,from:http://playerwelfare. worldrugby.org/?documentid=110

Ford, P.R., Webster, A., \& Williams, M.A. (2008). Skill acquisition and expertise mediates the relative age effect in sport. Paper presented at the NASPSPA 2008 Conference, Niagara Falls.

García Álvarez, V.D., \& Salvadores, J. (2005). El efecto relativo de la edad en el fútbol. Training fútbol, 115, 36-42.

Gonzáles-Villora, S., Pastor-Vicedo, J.C. (2012). Relative age effect in sport: Comment on Albuquerque et al. Perceptual \& Motor Skills: Motor Skills \& Ergonomics, 115(3), 891-894.

Gutiérrez-Díaz, D., Pastor-Vicedo, J.C., González-Víllora, S., \& Contreras-Jordán, O. (2010). The relative age effect in youth soccer players from Spain. Journal of Sports Science \& Medicine, 9(2), 190-198.

Hancock, D.J., Kelsey, S., Young, W., Bradley, Y.W., Weir, L.P., \& Stemarie, M. Diane (2013). Examining Mechanisms That Contribute to Relative Age Effects in Pre-Pubescent Female Ice Hockey Players. Talent Development \& Excellence, 5(2), 59-66.

Helsen, W.F., van Winckel, J., \& Williams, A.M. (2005). The relative age effect in youth soccer across Europe. Journal of Sports Sciences, 23(6), 629-636.

Loffing, F., Schorer, J., \& Cobley, S.P. (2010). Relative age effects are a developmental problem in tennis: but not necessarily when you're left-handed! High Ability Studies, 21(1), 19-25.

Magyar Úszó Szövetség (n.d.). Retrieved from http://musz.hu

Malina, R.M. (1994). Physical growth and biological maturation of young athletes. Exercise and Sport Sciences Reviews, 22, 389-434.

Medic, N., Starkes, J.L., \& Young, B.W. (2007). Examining relative age effects on performance achievement and participation rates of Masters athletes. Journal of Sports Sciences, 25, 1377-1384. 
Medic, N., Young, B.W., \& Medic, D. (2011). Participation-related relative age effects in Masters swimming: A 6-year retrospective longitudinal analysis. Journal of Sports Sciences, 29(1), 29-36.

Musch, J., \& Hay, R. (1999). The relative age effect in soccer: Cross-cultural evidence for a systematic discrimination against children born in late competition year. Sociology of Sport, 16, 54-64.

Musch, J., \& Grondin, S. (2001). Unequal competition as an impediment to personal development: a review of the relative age effect in sport. Developmental Review, 21(2), 147-167.

Nakata, H., \& SakaMoto, K. (2011). Relative age effect in Japanese male athletes. Perceptual and Motor Skills, 113(2), 570-574.

O’Donoghue, P. (2009). Relative age in elite tennis. Studies in Physical Culture and Tourism, 16(4), 379-388.

Okazaki, F.H.A., Keller, B., Fontana, F.E., \& Gallagher, J.D. (2011). The relative age effect among female Brazilian youth volleyball players. Research Quarterly for Exercise \& Sport, 82(1), 135-140.

Roberts, J.S., Fairclough, J.S. (2012). The Influence of Relative Age Effects in Representative Youth Rugby Union in the North West of England. Asian Journal of Exercise \& Sports Science, 9(2).

Rogel, T., Alves, I., França, H., Vilarinho, R., \& Madureira, F. (2007). Efeitos da idade relativa na seleçao de talento no futebol. Revista Mackenzie de Educaçao e Esporte, 6(3), 171-178.

Salinero, J.J., Pérez, B. Burillo, P., \& Lesma, M.L. (2013). Relative age effect in European professional football. Analysis by position. Journal of Human Sport Exercise, 8(4), 966-973.

Sherar, L.B., Baxter-Jones, A., Faulkner, R.A., \& Russell, K.W. (2007). Do physical maturity and birth date predict talent in male youth ice hockey players? Journal of Sports Sciences, 25(8), 879-886.

Vincent, J., \& Glamser, F.D. (2006). Gender differences in the relative age effect among U.S. Olympic development program youth soccer players. Journal of Sports Sciences, 24(4), 405-413.

AUTHOR'S ADDRESS:

\author{
Nikoletta Nagy \\ University of Physical Education, Budapest, Hungary \\ Department of Swimming \\ Alkotás Street 40 \\ 1123 Budapest, Hungary \\ Email: nniko21@indamail.hu
}

Received: 29 September 2015; Accepted: 15 October 2015 